\title{
Patient Preferences and Physician Practices for Laboratory Test Results Notification
}

\author{
Gil C. Grimes, MD, Michael D. Reis, MD, Gokul Budati, MD, \\ Manisha Gupta, MD, MPH, and Samuel N. Forjuoh, MD, DrPH
}

Introduction: This study assessed patient preferences and physician practices for laboratory test results
notification in ambulatory care.
Methods: Patients aged 18 years or older $(n=728)$ who were scheduled to see their primary care
physician at 5 clinics were offered the opportunity to participate in an anonymous survey during their
clinic visit. Their primary care physicians were also invited to participate in a separate online survey.
Questions on both surveys included the current method of laboratory test results notification and satis-
faction with the method.
Results: The majority of patients reported satisfaction with the current method of notification of nor-
mal results- the US mail-which was also the preferred method for notification of normal test results
by both patients and physicians. Direct phone contact by the physician was the preferred method for
notification of abnormal results by both patients $(64 \%)$ and physicians $(41 \%)$. Patients' preferred
method of notification of normal results significantly agreed with the current method (P < .0001),
whereas that of abnormal results did not $(P=.52)$.
Conclusions: Our findings indicate that patients and physicians both prefer the US mail for notifica-
tion of normal laboratory test results and a direct phone call by the physician for notification of abnor-
mal results. $(\mathrm{J}$ Am Board Fam Med $2009 ; 22: 670-676$. $)$

Effective patient-physician communication is the backbone of primary health care delivery. ${ }^{1-4}$ Its success depends on effective communication, notification of any relevant laboratory test results, and appropriate timely intervention resulting from it. ${ }^{5,6}$ The Institute of Medicine report "Crossing the Quality Chasm" suggested that enhancing the flow of information between patients and medical providers would help to reduce errors and improve quality. ${ }^{7}$ In addition, prompt communication of test results may help patients with their decision making. ${ }^{8}$

This article was externally peer reviewed.

Submitted 14 April 2009; revised 12 June 2009; accepted 18 June 2009.

From the Department of Family \& Community Medicine, Scott \& White Memorial Hospital and Scott, Sherwood, and Brindley Foundation, Texas A\&M University System Health Science Center, College of Medicine, Temple, TX.

Funding: This research was supported by a Scott \& White Institutional Research Fund (\#8744).

Prior presentation: Portions of the data were presented at the 33rd Annual Meeting of the North American Primary Care Research Group, Quebec City, PQ, Canada, October 15 to 18,2005 .

Conflict of interest: none declared.

Corresponding author: Samuel N. Forjuoh, MD, DrPH, Department of Family \& Community Medicine, Scott \& White Santa Fe Center, 1402 West Avenue H, Temple, TX 76504 (E-mail: sforjuoh@swmail.sw.org).
Communication to the patient of laboratory test results is a well-focused but less addressed issue. Lack of proper communication has led to ineffective health care delivery and patient dissatisfaction, which can potentially lead to malpractice litigation. The results of laboratory tests are often not communicated to patients because most physicians take a "no news is good news" approach to patient notification of laboratory test results. ${ }^{9}$ Moreover, Boohaker et $\mathrm{al}^{10}$ demonstrated that one third of physicians did not always notify patients of abnormal test results, whereas most patients $(>90 \%)$ wanted to be notified of all test results. ${ }^{9,11}$ This failure often results in the deterioration of patients' health and may lead to medical errors, as reported in a study of bone densitometry. ${ }^{6}$ This sequence of events has been highlighted through research about medical errors. ${ }^{12}$ A vast body of literature indicates that most patients want to be notified of all their test results, whether normal or abnormal..$^{9-11,13}$

Although the importance of the notification of laboratory test results for efficient patient care has been emphasized over the past several decades, ${ }^{1}$ no satisfactory method has been developed. A few studies have suggested that providing patients access to their medical records is an effective way to 
communicate test results. ${ }^{3,4,14}$ Most studies have concluded that patients generally prefer notification by mail. ${ }^{5,6,10,12,15}$ Mailing the results with an explanation of abnormal results has been reported as one solution. ${ }^{13}$ Reporting over the phone has been cited as a preferred method by a few studies. ${ }^{11}$ Some also emphasized that patients should discuss their preferences for laboratory test result notification with their providers. ${ }^{11,13}$ Notification during the follow-up appointment was also suggested in some studies. ${ }^{13}$

In the current study, we focused on patient and physician attitudes toward laboratory test results notification in ambulatory care. The issues addressed in this study were (1) the degree to which patients are notified of their laboratory test results; (2) methods that patients prefer for this purpose; (3) patient satisfaction with the current methods of notification; and (4) methods that physicians prefer to use to notify their patients of laboratory test results.

The inclusion of physician preferences, in particular, is a major contribution of this study to our current knowledge. Results of this study may assist with strategies to match physician methods of laboratory test results notification with patient preference. Finding a common method for the notification of laboratory test results that is acceptable to both providers and patients may lead to improved care, better patient satisfaction, and decreased risk of malpractice litigation.

\section{Methods}

\section{Study Design and Setting}

An anonymous survey was conducted in 5 of 13 primary care clinics of a multispecialty group practice associated with a 186,000-member health maintenance organization. These 5 clinics were the ones closest to the health maintenance organization's main hospital-Scott \& White Memorial Hospital in Temple, Texas. All of the clinics were also affiliated with the Central Texas Primary Care Research Network, a primary care practice-based research network located in Temple, Texas, within the Scott \& White Health Care System of the Texas A\&M Health Science Center College of Medicine. The Scott \& White Institutional Review Board reviewed and approved the study protocol and all participants signed a written informed consent before participation. However, the signed in- formed consent documents were not attached to the questionnaires and there was no key to link participant names to completed questionnaires.

\section{Study Participants}

Study subjects comprised patients and their family physicians. The family physicians were all employed by the Department of Family Medicine of the Scott \& White Health Care System. All patients were offered the opportunity to participate in an anonymous survey when they checked in or out of their appointment at any of the 5 study sites. We planned to enroll approximately 700 consecutive patients who presented at the 5 study clinics to see their physician during a 1-week period.

Questionnaires, which were available in Spanish and English, were administered by research assistants if the patients were unable to read or write. All 56 family physicians from the 5 clinics were also invited to participate in a separate online survey. They received 2 reminders to enhance participation.

\section{Assessment and Outcome Measures}

The patient survey included 20 questions, took approximately 15 minutes to complete, and collected data on the current method of notification of laboratory test results to them and their satisfaction with the current method. Data about patient attitudes about notification of laboratory test results, preference for notification of laboratory test results, as well as basic demographic data were also collected. The only open-ended question on the patient survey was a question asking for their age. Likert scale responses were used for the questions about satisfaction (very dissatisfied; somewhat dissatisfied; neither dissatisfied nor satisfied; somewhat satisfied; very satisfied) and frequency of notification of results (never; rarely; sometimes; most of the time; always).

Data from the physician subjects were collected via an Internet-based survey that included 13 multiple choice and 2 open-ended questions and took approximately 10 minutes to complete. The data focused on the notification of laboratory test results as well as the physician's satisfaction with the current method. Additional data were collected from the physicians regarding their attitude toward notification of laboratory test results and basic demographic data. The only open-ended questions were 
those regarding the year the physician completed their residency and their years in practice.

\section{Statistical Analysis}

The data forms were first checked for completion and accuracy and then sent to the Biostatistics Department for data entry and data quality check. Descriptive analyses were performed to compute frequencies and proportions of outcomes. Differences in outcomes were assessed by clinic and patient demographic variables. Reported satisfaction and frequency of notification were computed as combined responses of 1 to 3 on a 5 -point Likert scale. Group differences were assessed for significance using the $\chi^{2}$ or the Fisher's exact tests for categorical data and the nonparametric KruskalWallis analysis of variance test for ordinal (Likert scale) data. All tests were 2-tailed and considered significant at $P<.05$.

\section{Results}

\section{Characteristics of Study Participants}

Table 1 describes the patient population. Of the total patients $(\mathrm{n}=728), 33.5 \%$ were aged 18 to 39 years, $35.5 \%$ were aged 40 to 59 years, and $31.0 \%$ were aged 60 years or older. The majority were women $(66.4 \%)$ and single (71.1\%), with $11.3 \%$ being married and $17.6 \%$ being separated, divorced, or widowed. In addition, the majority was white $(74.4 \%)$, with African Americans and Hispanics representing $13.7 \%$ and $9.5 \%$, respectively. Most $(67.8 \%)$ had attended some college or were college graduates. They varied in their annual household income levels: $31.2 \%$ reported more than $\$ 60,000$ annually whereas only $16.3 \%$ reported less than $\$ 20,000$.

Of the physician participants $(\mathrm{n}=56)$, the majority were men (76.7\%); $44.6 \%$ were aged 30 to 39 years, $32.2 \%$ were aged 40 to 49 years, and $23.2 \%$ were 50 years or older. The majority $(60.7 \%)$ had completed their residencies between 1991 and 2000 and $41.1 \%$ communicated to some of their patients via e-mail.

\section{Notification of Laboratory Test Results}

Table 2 summarizes patient preferences for laboratory test results notification. The US mail was the preferred method for notification of normal test results $(31.7 \%)$, followed by a phone call by clinic staff $(23.7 \%)$ and a phone call by their physician
Table 1. Description of Patient Population $(\mathbf{n}=\mathbf{7 2 8}) *$

\begin{tabular}{lc}
\hline Variable & $\mathrm{n}(\%)$ \\
\hline Total & $728(100)$ \\
Gender & \\
Male & $244(33.6)$ \\
Female & $482(66.4)$ \\
Age (years) & \\
18-39 & $244(33.5)$ \\
$40-59$ & $259(35.5)$ \\
$\geq 60$ & $225(31.0)$ \\
Race/ethnicity & \\
White & $532(74.4)$ \\
African American & $98(13.7)$ \\
Hispanic & $68(9.5)$ \\
Other & $17(2.4)$ \\
Education & \\
Some high school & $43(6.0)$ \\
High school diploma & $189(26.2)$ \\
Some college & $274(38.0)$ \\
College graduate & $216(29.8)$ \\
Annual income (\$) & \\
×20,000 & $109(16.3)$ \\
20,001-39,999 & $178(26.7)$ \\
$40,000-59,999$ & $172(25.8)$ \\
Marital status & $208(31.2)$ \\
Single & \\
Married & $514(71.1)$ \\
Separated & $10(1.4)$ \\
Divorced & $66(9.1)$ \\
Widowed & $51(7.1)$ \\
\hline
\end{tabular}

*Numbers may not add to total because of missing data.

(22.8\%). For abnormal results, however, a phone call by their physician was the preferred method of notification for two-thirds of the patients, followed by a phone call by clinic staff and a follow-up office visit. Significant differences were observed for mail, e-mail, and phone preferences between normal test results notification and abnormal test results notification.

Although the vast majority of the patients (92.5\%) reported they would like to be notified of both normal and abnormal results, 58.7\% reported being currently notified of their normal results most of the time or always, whereas $21.3 \%$ reported they were never or rarely notified. The corresponding numbers for abnormal results were $52.5 \%$ and $9.8 \%$, respectively. The US mail $(31.5 \%)$ and phone call by clinic staff or physician $(31.3 \%)$ were the current most reported frequent 


\begin{tabular}{lccc}
\hline Method of Notification & $\begin{array}{c}\text { Normal Results* } \\
(\mathrm{n}=688)\end{array}$ & $\begin{array}{c}\text { Abnormal Results* } \\
(\mathrm{n}=700)\end{array}$ & $P$ \\
\hline US mail & $218(31.7)$ & $39(5.6)$ & $<.0001$ \\
E-mail & $37(5.4)$ & $11(1.6)$ & $<.001$ \\
Phone call by clinic staff & $163(23.7$ & $115(16.4)$ & $<.001$ \\
Phone call by physician & $157(22.8)$ & $450(64.3)$ & .0001 \\
Phone call by patient & $18(2.6)$ & $12(1.7)$ & .33 \\
F/U or office visit & $63(9.2)$ & $69(9.9)$ & .72 \\
No preference & $32(4.6)$ & $4(0.5)$ & $<.0001$ \\
\hline
\end{tabular}

${ }^{*}$ Data provided as $\mathrm{n}(\%)$.

$\mathrm{F} / \mathrm{U}$, follow-up appointment.

methods of notification; $24.7 \%$ of patients were notified during their follow-up visit. Most patients $(60 \%)$ were satisfied with the current method of notification.

Significant gender, age, racial/ethnic, educational, and income differences were observed for patients' first choice of method for being notifyied about normal test results. The first choice for male patients was a phone call by their physician whereas females' first choice was the US mail. Young patients generally preferred e-mail significantly more than older patients, as did more educated patients and those with annual household incomes of $\$ 60,000$ or more. Although white patients' first choice was the US mail, African American patients' first choice was a phone call by their physician and Hispanic patients' first choice was a phone call by clinic staff (Table 3).

Patients' preferred method of notification significantly agreed with the current method of notification of normal test results $(P<.0001)$ but not for notification of abnormal test results $(P=.52)$. It was interesting to note that $81.7 \%$ of patients were satisfied with their current family physician, although only $90.1 \%$ had a regular family physician. In addition, $73.4 \%$ rated their health as good or better. A significant concordance was observed for patient satisfaction with their current physician and their satisfaction with the current method of notification of normal results (Table 4).

Physicians' responses generally corroborated those of the patients, with $73.2 \%$ agreeing that patients should be notified of both normal and abnormal results. Although 78.6\% reported notifying their patients of their normal results, almost $100 \%$ reported notifying their patients in the case of abnormal results. The US mail (87.5\%) was the most practiced method of notification of normal test results, with $51 \%$ of physicians reporting satisfaction with the current method of notification, $39.3 \%$ reporting dissatisfaction, and $8.9 \%$ remaining neutral (reporting neither satisfaction nor dissatisfaction).

Physicians' preferred method of notification of normal results was the US mail (55.4\%) and their second choice was e-mail (17.9\%). Other reported choices were a phone call by the clinic staff $(14.3 \%)$, a phone call by the physician $(1.8 \%)$, or a phone call by the patient to the clinic (1.8\%). A minority of physicians $(8.9 \%)$ preferred a follow-up visit as their first choice to notify patients about their normal results. For notification of abnormal test results, physicians' first choice was a phone call by the ordering physician (41.1\%), followed by a phone call by a clinic staff other than the physician (30.4\%).

\section{Discussion}

Laboratory results notification has been well discussed but less well researched in the literature. Lack of consensus on the proper method of notification has led to many medical errors, ineffective health care delivery, and impaired patient-physician communication, which may ultimately lead to malpractice suits in some instances. ${ }^{6}$ Although some studies have been conducted in the past, ${ }^{5,9,11}$ no consensus has been derived from them that is universally accepted.

The importance of notifying laboratory test results is well documented. ${ }^{1}$ Direct patient notification may make patients proactive, enable them to take charge of their own health, and empower them to plan for follow-up. This will also make sure that 
Table 3. Patients' First Choice of Method of Notification of Normal Laboratory Results*

\begin{tabular}{|c|c|c|c|c|c|c|c|c|}
\hline Variable & $\begin{array}{l}\text { US } \\
\text { Mail }\end{array}$ & E-mail & $\begin{array}{c}\text { Phone Call by } \\
\text { Clinic Staff }\end{array}$ & $\begin{array}{l}\text { Phone Call } \\
\text { by Physician }\end{array}$ & $\begin{array}{c}\text { Phone Call by } \\
\text { Patient }\end{array}$ & $\begin{array}{c}\mathrm{F} / \mathrm{U} \text { or } \\
\text { Office Visit }\end{array}$ & $\begin{array}{c}\text { No } \\
\text { Preference }\end{array}$ & $P$ \\
\hline Gender & & & & & & & & $<.01$ \\
\hline Male & 24.4 & 7.6 & 23.1 & 25.3 & 3.6 & 13.8 & 2.2 & \\
\hline Female & 35.4 & 4.3 & 24.1 & 21.5 & 2.2 & 6.7 & 5.9 & \\
\hline Age (years) & & & & & & & & $<.001$ \\
\hline $18-39$ & 25.0 & 8.9 & 26.3 & 26.7 & 3.0 & 5.1 & 5.1 & \\
\hline $40-59$ & 44.5 & 4.0 & 19.0 & 17.0 & 2.4 & 9.3 & 3.6 & \\
\hline$\geq 60$ & 23.9 & 2.9 & 26.3 & 25.4 & 2.4 & 13.7 & 5.4 & \\
\hline Race/ethnicity & & & & & & & & .005 \\
\hline White & 34.3 & 5.7 & 24.6 & 21.8 & 2.2 & 7.1 & 4.4 & \\
\hline African American & 28.3 & 4.3 & 17.4 & 32.6 & 3.3 & 10.9 & 3.3 & \\
\hline Hispanic & 17.5 & 3.2 & 28.6 & 17.5 & 6.3 & 19.0 & 7.9 & \\
\hline Other & 26.7 & 13.3 & 6.7 & 20.0 & - & 20.0 & 13.3 & \\
\hline Education & & & & & & & & $<.001$ \\
\hline Some high school & 12.5 & - & 35.0 & 22.5 & 2.5 & 20.0 & 7.5 & \\
\hline High school diploma & 24.0 & 1.1 & 25.1 & 27.4 & 5.1 & 11.4 & 5.7 & \\
\hline Some college & 35.3 & 5.1 & 22.4 & 24.7 & 1.2 & 7.5 & 3.9 & \\
\hline College graduate & 38.2 & 10.4 & 21.2 & 16.0 & 2.4 & 7.5 & 4.2 & \\
\hline Annual income (\$) & & & & & & & & .005 \\
\hline$\leq 20,000$ & 20.6 & 2.0 & 26.5 & 29.4 & 3.9 & 10.8 & 6.9 & \\
\hline $20,001-39,999$ & 32.9 & 2.9 & 25.3 & 20.6 & 4.1 & 9.4 & 4.7 & \\
\hline $40,000-59,999$ & 29.8 & 5.6 & 26.7 & 25.5 & 1.9 & 6.8 & 3.7 & \\
\hline$\geq 60,000$ & 40.6 & 10.7 & 18.3 & 18.8 & 1.5 & 6.1 & 4.1 & \\
\hline Marital status & & & & & & & & .31 \\
\hline Single & 32.8 & 6.2 & 23.5 & 21.0 & 2.1 & 10.3 & 4.1 & \\
\hline Married & 29.1 & 2.5 & 21.5 & 30.4 & 5.1 & 5.1 & 6.3 & \\
\hline Separated & 44.4 & - & - & 44.4 & - & 11.0 & - & \\
\hline Divorced & 34.4 & 7.8 & 26.6 & 20.3 & 3.1 & 3.1 & 4.7 & \\
\hline Widowed & 21.3 & - & 25.5 & 27.7 & 4.3 & 12.8 & 8.5 & \\
\hline
\end{tabular}

*Numbers represent row percent.

F/U, follow-up appointment.

patients are notified promptly. ${ }^{6}$ The advantages with this procedure are that it reduces the workload, reduces the chances of missed diagnosis, and minimizes loss to follow-up. The concerns are that the patient would be unnecessarily frightened and would seek unreliable information. ${ }^{3,16,17}$

In this study, we found that a majority of the patients preferred to be notified of all laboratory

Table 4. Patient Satisfaction with Current Method of Notification and Current Physician $(n=636) *$

\begin{tabular}{|c|c|c|c|c|c|c|}
\hline \multirow[b]{2}{*}{$\begin{array}{l}\text { Satisfaction with Current } \\
\text { Family Physician }\end{array}$} & \multicolumn{6}{|c|}{ Satisfaction with Current Method of Notification } \\
\hline & $\begin{array}{c}\text { Very } \\
\text { Dissatisfied }\end{array}$ & $\begin{array}{l}\text { Somewhat } \\
\text { Dissatisfied }\end{array}$ & $\begin{array}{l}\text { Neither Satisfied } \\
\text { nor Dissatisfied }\end{array}$ & $\begin{array}{l}\text { Somewhat } \\
\text { Satisfied }\end{array}$ & $\begin{array}{c}\text { Very } \\
\text { Satisfied }\end{array}$ & Total \\
\hline Very dissatisfied & 30 & 12 & 1 & 6 & 9 & 58 \\
\hline Somewhat dissatisfied & 2 & 8 & 4 & 6 & 3 & 23 \\
\hline Neither satisfied nor dissatisfied & 3 & 8 & 8 & 12 & 5 & 36 \\
\hline Somewhat satisfied & 12 & 18 & 9 & 24 & 30 & 93 \\
\hline Very satisfied & 54 & 50 & 36 & 99 & 187 & 426 \\
\hline Total & 101 & 96 & 58 & 147 & 234 & 636 \\
\hline
\end{tabular}

${ }^{*} P<.001$. 
test results, whether normal or abnormal; this has also been reported by others. ${ }^{9} 11$ For example, the studies by Meza and Webster ${ }^{9}$ and Baldwin et $\mathrm{al}^{11}$ both reported that $90 \%$ of patients preferred to be notified of all test results, compared with $93 \%$ in this study. Although both patients and physicians preferred the US mail to communicate normal results, a phone call by the clinic staff and e-mail were their respective second choices. The US mail was also cited as the preferred method in the Boohaker study ${ }^{10}$ as well as several others. ${ }^{5,6,12,15}$ In addition, the current method of notification of normal laboratory test results was consistent with that preferred by both patients and physicians. Both preferred a phone call by the physician to notify of abnormal results; a phone call by clinic staff other than physician was the second choice. The satisfaction levels were higher with the management of normal test results than that of abnormal results. We also found interesting demographic trends never before reported, to the best of our knowledge, such as men having a preference for a phone call by their physician for notification of normal results whereas women preferred the US mail. The significant concordance of patient satisfaction with their current physician and their satisfaction with the current method of notification of normal results makes intuitive sense.

Although the preferred method of notification of normal laboratory results, the US Mail, is the same as the current method, the notification of abnormal laboratory results needs some attention. The current method of notification of abnormal test results was satisfactory to the majority of patients, but the method most preferred by patients and physicians was a phone call by the ordering physicians to the patients. This interactive feedback can help to bring about any immediate intervention, if required. Also, it would improve patientphysician communication ${ }^{1-4}$ and possibly lead to better patient outcome.

To protect the physician from legal problems, notification should be documented ${ }^{1}$ along with any advice given by the physician. A few previous studies have found that telephone communication, although preferred by many patients, is not feasible for many physicians because of their limited time. ${ }^{18}$ If the information is passed over the phone by staff other than the physician, there may be a danger of misinterpretation. It may also be preferable that the patients discuss their preferences over notification with the providers during an appointment. ${ }^{11}$

The various methods of notifying patients of test results have advantages and disadvantages. Although a letter automatically documents the communication in the medical record, this may not be true of a phone call or an e-mail. Whether a message ought to be left on an answering machine or the patient asked to call back has not been resolved to date, particularly in the wake of current Health Insurance Portability and Accountability Act regulations.

The extent to which these findings can be generalized is unknown because we only studied a single specialty in a single geographic location. Nonetheless, we recommend that patients should be notified of all laboratory results. Normal results should be notified by mail and abnormal results should be communicated over the phone by the physician.

Limitations of this study included the fact that the financial burden on the hospital and the patients as well as the time management of the physicians, patients, and the clinic staff were not considered. In addition, we used self-reported data that may not correlate with actual behaviors and practices. We did not do any multivariate analyses to adjust for significant associations uncovered in bivariate analyses because we did not feel that we had all the plausible confounders in this study. Finally, although these same issues with laboratory test results notification may apply to radiographs, electrocardiograms, and curbside consults, this study focused on laboratory test results. Therefore, further studies are recommended to overcome these shortfalls.

\section{Conclusions}

Findings from this study corroborate those of previous ones that patients would like to be notified of all their laboratory test results. The US mail was found to be a satisfactory method for the notification of normal results by both patients and physicians. We also found a concordance of satisfaction with current physician and current mode of notification of normal results.

We thank Sonia Holleman for study coordination and Phyllis Davis for providing secretarial support. 


\section{References}

1. Lawrence J. Do you always make sure patients get test results? Manage Care 1996;4:37-41.

2. Karen R, Muret-Wagstaff S, Goldman DA, Mandi KD. Notifying emergency department patients of negative test results. Pediatr Emerge Care 2003;19: 226-30.

3. Ross SE, Lin CT. The effects of promoting patient access to medical records: A review. J Am Med Inform Assoc 2003;10:129-38.

4. Ferreira A, Correia A, Silva A, et al. Why facilitate patient access to medical records. Stud Health Technol Inform 2007;127:77-90.

5. Schofield MJ, Sanson-Fischer R, Halpin S, Redman S. Notification and follow up of pap test results: current practice and women's preferences. Prev Med 1994;23:276-83.

6. Cram P, Rosenthal GE, Ohsfeldt R, Wallace RB, Schlechte J, Schiff GD. Failure to recognize and act on abnormal test results: the case of screening bone densitometry. Jt Comm J Qual Patient Saf 2005;31: $90-7$.

7. Institute of Medicine. Crossing the quality chasm: a new health system for the $21^{\text {st }}$ century. Washington, DC: National Academy Press, 2001.

8. Davey HM, Barratt AL, Davey E, et al. Medical tests: women's reported and preferred decision making roles and preferences for information on benefits, side-effects and false results. Health Expect 2002;4:330-40.

9. Meza JP, Webster DS. Patient preferences for laboratory test result notification. Am J Manag Care 2000;6:1297-300.

10. Boohaker EA, Ward RE, Uman JE, Mc Carthy BD.
Patient notification and follow-up of abnormal test results. Arch Intern Med 1996;156:327-31.

11. Baldwin DM, Quintela J, Duclos C, Staton EW, Pace WD. Patient preferences for notification of normal laboratory test results: a report from the ASIPS Collaborative. BMC Fam Pract 2005;6:11.

12. Poon EG, Gandhi TK, Sequist TD, Murff HJ, Karson AS, Bates DW. "I wish I had seen this result earlier!": dissatisfaction with the test result management systems in primary care. Arch Intern Med 2004;164:2223-8.

13. Peres M, Wellman M. Notification of Papanicolaou smear results: a survey on women's experiences and preferred means of notification. Aust $\mathrm{N} Z \mathrm{~J}$ Obstet Gynaecol 2001;41:82-5.

14. James PA. Managing patient information longitudinally. J Fam Pract 2000;49:716-7.

15. Del Mar CB, Wright RG. Notifying women of the results of their cervical smear tests by mail: does it result in a decreased loss to follow-up of abnormal smears? Aust J Public Health 1995;19:211-3.

16. Priyanath A, Feinglass J, Dolan NC, Haviely C, Venta LA. Patient satisfaction with the communication of mammographic results before and after the Mammography Quality Standards Reauthorization Act of 1998. AJR 2002;178:451-6.

17. Sung S, Forman-Hoffman V, Wilson MC, Cram P. Direct reporting of laboratory test results to patients by mail to enhance patient safety. J Gen Intern Med 2006;21:1075-8.

18. Couchman GR, Forjuoh SN, Rascoe TG, Reis MD, Koehler B, Van Walsum KL. E-mail communications in primary care: what are patients' expectations for specific test results? Int J Med Inform 2005;74: 21-30. 